\section{Advancing the Standard of Cancer Care in 2014}

\author{
Robert W. Carlson, MD
}

The NCCN hosted our 19th Annual Conference: Advancing the Standard of Cancer Care at The Westin Diplomat in Hollywood, Florida, March 12 through 16, 2014. We present these Highlights as a synopsis of the proceedings in this special issue of JNCCN-Journal of the National Comprehensive Cancer Network.

The 3 days of the NCCN 19th Annual Conference included a variety of educational activities. The latest updates in clinical practice decision-making were presented, including updates to the NCCN Clinical Practice Guidelines in Oncology (NCCN Guidelines). Attendees participated in presentations on more than 15 disease types, including breast, non-small cell lung, and prostate cancers, chronic myelogenous leukemia, and melanoma, as well as patient management and supportive care topics. For example, this special edition includes a presentation on "Genetic Counseling in Patients with Familial Risk for Colorectal Cancer," a topic that was translated into new NCCN Guidelines for Genetic/Familial High-Risk Assessment: Colorectal in February 2014.

Another interesting discussion centered on "Early Detection of Prostate Cancer: Do the Benefits Outweigh the Consequences?" During this point/counterpoint presentation, Peter R. Carroll, MD, MPH, and Andrew J. Vickers, PhD, discussed the controversy of over-screening in prostate cancer, emphasizing the importance of selective early detection and selective treatment based on patient and risk factors. In addition, Drs. Carroll and Vickers explained that, while prostate cancer screening remains controversial, the NCCN Guidelines for Prostate Cancer Early Detection limit overdetection and overtreatment.

This year's Highlights also include summaries of 2 of the now-seminal NCCN Roundtables. The first, titled, "The Child's Experience When a Parent has Cancer" was moderated by Lillie D. Shockney, RN, BS, MAS. It is often recognized that cancer in an individual is a family and a community disease, and no person in the family and community is impacted more than the children, especially when young. This roundtable focused on these children - their challenges and what the health care team can do to support them through their experience. It included notables such as Martha Aschenbrenner, MA, The University of Texas MD Anderson Cancer Center; Bruce Ham, Single Fathers Due to Cancer Support Group, UNC Lineberger Comprehensive Cancer Center, and author, Laughter, Braids and Tears; Paula K. Rauch, MD, Massachusetts General Hospital; Zoraida Sambolin, Emmy Awardwinning journalist and former co-anchor for CNN's "Early Start"; and Maya Silver, co-author, My Parent Has Cancer and It Really Sucks.

The second roundtable brought together an expert panel representing a diverse group of stakeholders to explore the Affordable Care Act (ACA) and health care reform in the United States. The ACA is a transformational event for health care in the United States and has multiple dimensions and impacts on health care, the economy, and society. This impact is already being felt, while additional effects will become apparent in the future. Oncologists and other health care providers will experience many changes, direct and indirect, anticipated and unanticipated.

To discuss this important and far-reaching public policy, its effect on the oncology landscape, and assessment of risk for providers, payers, and patients, moderator Clifford Goodman, PhD, of The Lewin Group, was joined by Christian G. Downs, JD, MHA,

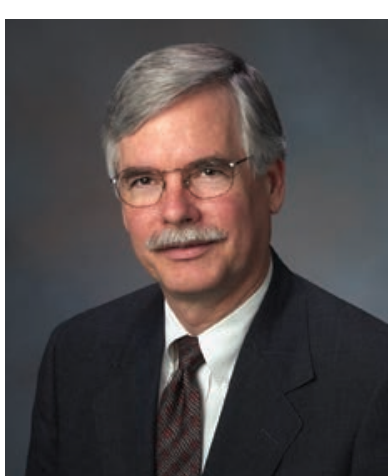

Robert W. Carlson, MD

Robert W. Carlson, MD, joined NCCN as CEO in January 2013 after numerous leadership positions, including chair of the NCCN Breast Cancer Panel and several NCCN Task Forces. He has also been a member of the NCCN Breast Cancer Risk Reduction Panel, Breast Cancer Disease-Specific Executive Committee, CME Advisory Committee, Guidelines Steering Committee, and Board of Directors. Previously, Dr. Carlson was Professor of Medicine in the Division of Oncology and Stanford Medical Informatics at Stanford University Medical Center. Dr. Carlson received his medical degree from Stanford University Medical School and completed his internship and junior residency in internal medicine at Barnes Hospital Group in St. Louis. He returned to Stanford for his senior residency and postdoctoral fellowship in medical oncology. Dr. Carlson is board certified in internal medicine and holds a subspecialty certification in medical oncology. Dr. Carlson is a member of several medical societies. He lectures extensively and has authored or co-authored over 130 articles, abstracts, and book chapters. He is also Associate Editor of Oncology and JNCCN.

The ideas and viewpoints expressed in this editorial are those of the author and do not necessarily represent any policy, position, or program of NCCN. 
Association of Community Cancer Centers; Liz Fowler, PhD, JD, Johnson \& Johnson; Michael Kolodziej, MD, Aetna; Lee H. Newcomer, MD, MHA, UnitedHealthcare; John C. Winkelmann, MD, Oncology Hematology Care, Inc., and American Society of Hematology; Mohammed S. Ogaily, MD, Henry Ford Health System; and W. Thomas Purcell, MD, MBA, University of Colorado Cancer Center.

While diverse, all the NCCN Annual Conference presentations focus on furthering the mission of the NCCN to improve the quality, effectiveness, and efficiency of cancer care so that patients can lead better lives. To that end, the NCCN Annual Conference remains only one of many NCCN efforts.

In this past year, NCCN has strengthened its foundation to continue work on implementing the new strategic plan, which focuses on goals and initiatives for the next 5 years. The strategic plan will enhance the usefulness of the NCCN Guidelines and related information products.

For example, NCCN continues our initiative with McKesson Specialty Health to develop value-based pathways for the treatment of common cancers. These clinical practice guidelines are jointly developed by McKesson Specialty Health, The US Oncology Network, and NCCN to consider efficacy, toxicity, and cost when evaluating treatment options in radiation oncology, and are based on the NCCN Guidelines.

Our international program has also continued to grow, and NCCN recently launched the NCCN International Educational Activities Program, which recognizes non-U.S. physicians who have demonstrated understanding of the NCCN Guidelines via completion of required educational activity hours. NCCN also continues to work in collaboration with third party organizations to present the NCCN Guidelines to international audiences of clinicians and other medical professionals. Additionally, NCCN collaborates to create and distribute International Adaptations and Translations of the NCCN Guidelines, which may include modifications representative of metabolic differences in populations, technologic considerations, and regulatory status of agents used in cancer management, such as availabilities of drugs, biologics, devices, and procedures.

Recently, NCCN announced the availability of the NCCN Guidelines for Patients: Breast Cancer Stages 0-IV-the latest addition to the library of NCCN Guidelines for Patients available online free-of-charge at NCCN.org/patients. This is the first comprehensive stage-specific library of NCCN Guidelines for Patients, and joins the NCCN Guidelines for Patients on colon, esophageal, non-small cell lung, ovarian, pancreatic, and prostate cancers; caring for adolescents and young adults; chronic myelogenous leukemia; malignant pleural mesothelioma; melanoma; multiple myeloma; and lung cancer screening. NCCN Guidelines for Patients are made possible by charitable donations to the NCCN Foundation.

These are just a few of the programs and initiatives in the works and on the horizon. Through these programs and initiatives, NCCN aspires to be the world leader in defining and advancing high-quality, high-value cancer care. But none of that is possible without the contributions and support of our member institutions and of the larger oncology community. We believe that JNCCN readers, whether you are from a member institution or not, also contribute to improving the quality of cancer care. We embrace this collaboration and partnership, and look forward to working with you now and in the future.

Your support of NCCN and our programs is invaluable, and I hope that you will continue to participate in the NCCN Annual Conference (March 12-15, 2015) and other NCCN activities and programs. Please visit NCCN.org for more information and to access programs such as the NCCN Guidelines and to watch, and participate in, NCCN's continuing evolution. 